acoond examination, I detected another bag of membranes, and a second head presentation. On rupturing this bas, a second child was speedily born. On exploring the abdomen with $m y$ hand, I could detect another foetus in utero; consequently, I again made an examination per vaginam, and then discovered another bag of membranes entire, and transverse presentation. I then ruptured the membranes a second time, and turned the child. Thero was but one placenta, and that not an unusually large one.

After a short labour of a few hours. the woman was safely delivered of three full grown male children. One lived twelve hours; another, twenty-four; and the last survived three days. This was the woman's first confinement.

\section{ON THE MURMURS OF THE HEART AND GREAT VESSELS.}

By R. Hotchixson Poweln, M.D.Lond., Physician to the Royal Infirmary for Diseases of the Chest.

[Coucluded from page 107.]

Trn preceding statements show, at all events, that we have still to discuss the first principles of cardiac action, and preclude mere dogmatising, as opposed to observation. If it be a fact that the impulse of the heart and the arterial pulse are not iso-chronous, even allowing for the fractional moment consumed in overcoming vascular elasticity, also for the retarding effect of regurgitant disease, it will be necessary to re-state and re-arrange the respective movements and sounds as regards diagnosis. Thus, in obstructive valvular (mitral) disease, cardiac murmur will not coincide with ventricular contraction, but with dilatation and impulse. The relation held to exist between impulse, first sound, systole, and pulse, becomes necessarily disjointed; the two former phenomena being first, the two latter next, and the second sound last, in order. As regards the causation of the heart's sounds, any person may convince oneself of their very simple character-being rather tactile shocks, perceptible to the ear, than true acoustic soundsby tapping the palm when covering the ear, which very closely simulates them, especially the first sound. Much of the obscurity in question may be ultimately cleared up by attending to circumstances connected with cardiac phenomena, when disease results in the walls, orifices, or valves of the heart. This leads us to advert to the mode of production of cardiac murmurs, and I may here call attention to the close correspondence, if not agreement, existing between the opinions broached by Dr. Corrigan and the deductions of Professor Kiwisch. A quotation from Volkmann will again assist us.

It will be observed that the pressure is regulated by proximity to, or distance from the heart, also by the diameter of the tube, and determinate friction of the contained fluid. The undulatory movement in the vessels somewhat resembles that described by Skoda in the exposed infant's heart. It follows, moreover, that the proclivity to the production of murmurs in the circulatory system is influenced in a corresponding degree, as below referred to.

"The laws regulating the movement of the blood, in the living organism, are identical with those determining the movement of fluids in artificial tubes; the logical element being the same in both. The lateral pressure results from the adhesion and friction occurring between the liquid and the parietes of the tubes. This lateral pressure, at any one point of the tube, being proportional to the resistance to be overcome by the movement of the water (or other fluid) at this point.

"The lateral pressure, exerted at different points of a tube of uniform dimensions, is inversely as their distance from the discharging orifice; the ratio of the length of the tube to the lateral pressure appears constant; but the lateral pressure is almost inversely as the diameter of the tube: yet this pressure increases as the width diminishes, the pressure not being uniform throughout the arterial system, as asserted by Poisseuille.
"The pressure of the blood is subject to a gradual diminution from the commencement of the arterial to the termination of the venous system; points equidistant from the centre of motion, suffer varying degrees of pressure, which is increased in parts through which the blood passes with difficulty; the capillaries, occupying an intermediate position, suffer over half the maximum near the heart.

"To distension of a tube, caused by intermittent injections, succeeds contraction, dependent upon its elasticity both movements do not take place simultaneously throughout, but by undulations from one end to the other; this wave-like motion being essential to the formation of a current.

"The blood pressure is equal to one quarter of that of the atmosphere, varying with the distance of the tubes (arterial, capillary, or venous) from the point of departure, and with the species of animals; the variation ranging from a third to an integral number in mammals.

"Warm-blooded animals possess a greater arterial pressure than the cold-blooded, being lowest in carly and advanced, and highest in the prime of life, and not being in proportion to the size of the animal.

"The velocity of the blood-current (as distinguished from the space traversed by a blood particle in a given time) is considerably greater in the arteries than that in the capillaries; being at a maximum in those in propinquity with the heart, but not being identical in the analogous vessels of different animals, yet not varying more than in animals of the same species; the mean relocity in the carotids of mammals being about twelve inches per second."

I next subjoin a resumé of Kiwisch's deductions; which, though not devoid of some obscurity and apparent contradiction, are rery valuable, and closely applicable to the subject in hand.

"Elastic membranes in the vessels give tone or murmur under two conditions; either when thrown into ribration by an external influx (tone), or being relaxed, are suddenly made tense (murmur). The motion of the blood in the vessels of itself never gives rise to sound; sounds heard in them entirely resulting from the movements of their walls, produced by the fluid in motion. Sounds pass into murmurs from unequal tension and irregular vibrations. In a vessel of unequal calibre, vibrations and sounds arise, which are either tones or murmurs, according to their rapidity. The blood-current preserves its shape when passing into a wider space and less tense tube; the elasticity of the tube causes contraction, then expansion, and again contraction; and thus successive movements, if sufficiently rapid, produce sound, its kind depending upon the parietal thickness, width, and form of the column, and not being produced in the narrow, but wider succeeding point.

"All vascular bruits are pre-eminently occasioned", $\mathrm{Dr}$. Kiwisch states categorically, "by the inequality of space in the bore of the ressel, and by the unequal tension of the latter. A determinate acceleration of the sanguineous current, and a relative peripheral diminution of the blood column, are conditions more remotely concerned in their production.

"The inequality of space is produced most frequently by a partial compression of the arteries, more rarely by the augmentation of their diameter.

"The vascular bruits observed in chlorotic subjects, like those heard in the abdomen during pregnancy, are mark edly phenomena of compression.

"Bruits are never produced in the veins, but are invariably to be sought for in the arteries.

"According to this view, there exists, then, in the arteries, continuous murmurs, that is to say, systolic and diastolic sounds are therein produced."

[Many of the above deductions, it will be remarked, differ from the views previously held as to venous and placental murmurs, and require confirmation.]

"In the vascular parietes, during health (?), diminution of the muscular contraction in the vessels, and imporerished blood, are the chief elements giving rise to vassular murmurs. 
"Those abdominal murmurs heard in pregnant females are slowly diffused in the arteries of the integument; the term 'placental, or uterine bruit,' should be replaced by "bruit of the abdominal integuments."

This latter murmur is not a phenomenon peculiar to pregnancy; but, under favourable circumstances, it is met with in other uterine growths, and in some rare cases of ovaninn tumour, when united with considerable displacement of the uterus.

Iet us now compare these statements with Dr. Corrigan's opinions (from Abstract of Lectures on the Theory and Practice of Medicine, by R. II. P.).

"The seusation termed 'thrill' always denotes disease, and is perceived by the sense of touch. The morbid sounds observed by the ear arise from the same cause. All the different sounds, generically called 'bruits', have a similar common origin. They all depend upon an irregular currentlike motion of the blood, and are invariably accompanied with a flaccid state of the parietes of the vessels. Fremissement, or thrill, of aneurism may be produced artificially by pressure made on any large vessel, as the femoral artery, as it escapes from Poupart's ligament-the finger being placed below, the sensation is immediately perceived; the parietes are made flaccid, and thrown into vibrations from the irregular streams of blood induced. Bruit may be present without thrill; the artery must approach closely to the parietes to occasion this latter phenomenon, which, however, is never found without the presence of bruit. This sound may be conveyed when the vessel is too far off for fremissement to be felt. All the fine distinctions of bruit are useless; these morbid sounds were by Laenuec supposed to arise from spasm of the arteries; but spasm never takes place in these tubes; moreover, it could not continue for years, and, again, these bruits are induced by pressure. Others held that these abnormal phenomena were produced by narrowing (which is not present) of the vessels (Bertiu); and by the stream of blood being pressed upon in passing from a larger to a smaller space (Elliotson), by viscid blood (Magendie), and by constriction of the vessels and increased resistance to the current blood (Dr. Williams, in British Association). The latter view (rationale of increased resistance) is untenable, as in patency of the aorta, the sound continues after venesection, although the resistance be overcome. Again, where a large quantity of blood is lost, we have bruit; the reverse should take place were resistance the cause. In chlorotic females there is bruit.

"The equipoise between the pressure and the velocity of the current becomes disturbed, and friction ensues between the blood and parietes, giving rise to vibrations. Hence, the irregular impulsion of the blood into the flaccid ressel conveys to the touch the sensation of vibration or thrill, and to the ear, through the stethoscope, the bellows murmur. Blood is a non-elastic fluid in relation to the force exerted on it; and if the sides of the vessel be sufficiently tense, as in the natural state, when the blood fills the artery, no vibrations can ensue, as the motion of the blood has no attendant sound. But if the supply of fluid be diminished, so that it does not fill the tube, it moves with an irregular whirling motion, and induces vibration, with murmurs in the parietes. These peculiar conditions are essential. Irregular motion of the fluid is not sufficient to cause bruit; as when an artery opens in to a large aneur ismal sac, there is a whirling motion of the blood within but no sound results from the parietes being uniformly applied to the fluid. Loud bruit is induced when the aneurismal dilatation extends to the mouth of the aortin and the valves are unable to close the opening; the blood, now regurgitating, leaves the parietes flaccid, so that the next pulsation gives rise to the bruit. Thus, in aneurism of the aorta, no morbid sound is heard unless the valves permit regurgitation. In narrowing of the auriculo-ventricular opening, the fluid is thrown from the auricle into the ventricle with great force, diverging into radii of different velocities, the ventricle being previously emptied by contraction. In this case, the sides of the ventricle are relaxed, and the blood-stream is irregular. Narrowing of an orifice is nan-essential in the production of bruit, as before stated. In insufficiency of the semi-lunar valres, causing permanent patency of the aorta, the regurgitant blood leaves the arterial tubes in a state to generate the bellow murmur in the next pulsation of the heart. In aneuriom by anastomosis - of which there are two kinds (1st), tumours formed by a congeries of large blood-vessels-the morbid sound is very loud when the blood is expelled on remoral of the pressure of the fingers; (2nd) it is also heard in common varicose aneurism; the sides of the veins are peculiarly favourable for vibration and sound when the blood rushes in. In pregnant females it is not caused by pressure on the arterial trunks, existing only on one side; the nterine arteries being thin, and entarged, and opening by wide mouths into the sinuses of the veins, irregular currents are induced in these tortuous vessels. (Dr. Kennedy gave the particulars of the case of a pregnant woman, where the uterus had protruded between the recti muscles, and was only covered by integuments. It formed a large tumour, which reached down to the knee. On one side, bruit was clearly heard, and frémissement could be distinctly felt. After delivery, it was found that the placenta corresponded with the site over which these signs were perceived.) After large depletions, irregular currents are produced by the arteries not being filled, and the blood not being duly supported by the walls of the vessels; hence, the peculiar jerking pulse after hæmorrhage. The same conditions and attendant signs are also found in chlorotic and nerrous females; there is an irregular motion of the heart, and the blood is irregularly propelled into the vessels."

Dr. Corrigan contends (Dublin Medical Journal), in opposition to Dr. Williams's objections-that bruit is still produced, even after the cutting off and removal of the tube heyond the contracted point (at the extremity of the tube discharging fluid) - that the surrounding air then takes the place of the flaccid parietes, and responds to the vibrationgenerating stream.

Time will not admit of a careful collation of these sereral conclusions, so as to eliminate the points of agreement from divergent matter. The chief elements most obviously concerned in the inquiry involve the tenuity and other conditions of the vascular parietes, the calibre of the ressels, the amount, velocity, and quality of the blood, as well as the degree of friction, with corresponding pressure, set up between the current and the tube. What element plays a merely subsidiary part, what is to be altogether excluded in the link of causation, and what takes a predominant part, are the main circumstances giving rise to difference of interpretation, and constitute the paramonnt questions upon which the above authorities are at issue. Kiwisch's deductions narrow the discussion, and, in some respects, embrace the obstructive (Williams) and flaccid (Corrigan) theories. He gives a predominant share to the latter, although not setting it down as the exclusive source of murmur. Dr. Corrigan's views are further supported by Kiwisch's assigning great value to the originating influence of the (whirling C.) blood-stream, giving rise to murmur attaching to a free or obstructed neck of tube indifferently, provided unequal tension be present, and coexist with disproportionate space. Volkmann's laws, above quoted, farour the latter explanation, in showing the relation existing between the diameter of a tube, taken in apposition with the velocity and friction of its contents, and the respective gradations of resistance and pressure existing throughont the circulatory system.

In conclusion, I have to apologise to the Society for the great though unavoidable length of these quotations, as well as for the fragmentary character of this paper, which is merely suggestive, and intended to furnish material, in a very condensed form, for discussion. I see members eminent for their physiological researches in this department present, by the expression of whose opinions the Society will be highly faroured,

[At the discussion which took place after reading the above paper, a case was mentioned by Mr. Hodgaon, in 
which the thoracic parietes were blown off by an explosion, befalling one of the insurgents at the July insurrectionary outbreak in Paris. The heart was denuded, and observations then made seemed to favour Magendie's views. Mr. Hodgson also stated that the movement of a denuded artery wras very slight, if any; the pulsation being invisible, and that imparted to the fingers, conveying an imperfect and deceptive impression. 'Th. Weber's recent experiments (Med. Chir. Revier, Jan. 1856) further confirm the above doctrines; in showing that vascular sounds are dependent on the vibrations excited in the walls by the moving fluid, the friction of whose particles inter se has no effect; that thinness of the walls, their width, and the greater fluidity of their content, bear a direct proportion in the production of sound; that narrowing of a tube farours this, especially when transition into a wider tube is attended with a certain velocity of movemeut, which is indispensable, sound being principally effected by the walls of the tube-the more dense and elastic, thc better the conduction. It is to be hoped that advantage has been taken of Crimean opportunities to clear up many doubtful points and still unsettled views attaching to cardiac phenonena.]

\section{feristope.}

\section{STRGERT.}

\section{SURGICAL OPERATIONS IND THFPAPEUTICS.} StrGICAL vises of GLYCLRrNF.

Is the number of this Jours.ar for January 10th, we noticed some observations made by $M$. Demarquay on the surgical applications of glycerine. Since M. Demarquay published his remarks, further experiments have been made on the subjeet, the result of which $M$. Letros has published in the Gazette Médicale de Paris for January 26th. He describes first the physical, and then the therapeutic effects, of glycerine.

r. Physical Effects. Being of an oily appearance, while it is of the consistence of syrup, it prevents the dressings from adhering to the wound; and, by its solubility in water, it allows the wounds to be readily cleaned. Glycerine evidently moderates suppuration; and on the other hand, being very hygro metric, it keeps the parts constantly moist, and prevents the products of exudation from concreting. To oltain this result, it is necessary to apply the glycerine in abundance, and to impregnate the chapie and linen well with it. It protects the parts from the action of the air, and maintains them at a sufficiently high temperature In these respects, glycerine is superior to fatty matters for surgical dressings.

II. Therapbutic Uses. The first effect of the application of glycerine is to produce a slight pricking seusation, which, however, is soon calmed, and is never very distressing.

Simple Wounds. In ordinary wounds, whether accidental or surgical, and free from complication, glycerine has no very manifest action. Under its application, wounds heal at least as soon as under most nentral local applications, and almost the only circumstance of any note is the small amount of suppuration. Besides this, there is scarcely ever an exuberance of granulations.

Burns. In the different degrees of burns, glycerine is a very convenient and efficacious application. Patients who have been treated by the transcurrent cautery, on account of white swelling, sciatica, etc., have objected to be dressed with glycerine, on the ground that the hurn healed too quickly, and did not "draw" enough. The bappy effect of glycerine has been remarkably observed in a case of burn in the second degree, produced by an explosion in a mine.

Diphtheritis of Wounds. In the Hospital of St. Louis, wounds, during the first days of their production, present greyisb, almost diphtheritic appearance, and become clean slowly. Under the influence of glycerime, this condition, mare troublesome than serions, is arrested; the wound assumes a rosy aspect, without any exuberance of granulations.

Hompital Gemprene. It was for this affection that glycerine was first employed in the Hospital of St. Louis. The disesse in the first case was very extensive, and had been unsuccess. fully treated by lemon.juices, quinine, and even by strong nitrie acid and the actual cautery. In this, as in two other cases, glycerine was conpletely successful.

Abscesses and Purulent Deposits. In deep rounds and sinuous ulcers, glycerine has been used, either by being introduced on a piece of charpie, or as an injection. The amount of suppuration has been remarkably diminished, and the period of cicatrisation has been smaller. M. Demarquay has also injected olycerine into cold and congestive abscesses, and those in connexion with inflamed bones, with complete success.

Dlcers. Clironic, virrieose, gangrenous, and other ulcers, have bocome rapidly clean under the influence of glycerine. The surface throws out granulations, and cicatrisation soon takes place. Rest is a powerful and necessary aid.

Chancres. Glycerine, though it has no specitic action on chancres, rapidly cleans the surface, and canses them to assume a healthy appearance.

Diseases of the Neck of the lterus. MII. Tronssean and Aran have already employed glycerine, but with littlo setisfaction, in uterine affections. N. Demarquay, however, has found it useful in simple or granular ulceration of the cervix. When the ulceration has been chronic, or when the cervix was rather enlarged and tumetied, caustic applications were also made. Cilycerine was then applied by means of radding: after the separation of the eschar, the secretions, enmmonly so abundant and fotid, were renarkably moderate in quantity.

In vaginitis, also, glycerine has been applied; but here, as in diseases of the cervix uteri, nothing conclusive can as yet be arrived at regarding its efticacy.

THE WaHA DATU LF THE TREATMEST OF wotNDS, ESPEchatr THOSE MADE IN AMUCTATION.

M. Lasgrasick, of Berlin, has published in the Deutsehe Nilinik for September 15th, 1855, an uccount of a process by which wounds, especially those made in amputation, can be constantly subjected to the influence of 8 warm bath. He first examines the modes of application of cold and warm water, and concludes that, in many cases, these are insufticient. He re. lates the advantages which he has obtained from the use of large warm baths after capital operation, such as disarticulation of the shoulder-joint, excision of the scapula, lithotomy, etc. These baths have been einployed from half an hour to an hour once or twice daily, not being contraindicated by traumatic fever and intlammation of the edges of the wound; at a temperature of $97^{\circ}$ Fabrenheit, they maintain warmth, diminish fever, heat, and the frequency of the pulse, calm pain, and keep the wound clear. Topical warm baths have often been employed by MM. Langenbeck and Stromeyer, in gun-shot wonnds of the extremities, with or without injury of the bones, before and during suppuration. Stromejer first recommended the use of the permanont warm bath after the operation for vesicovaginal fistula

The following is a description of the apparatus emplojed by M. Langenbeck:-

The apparatus intended for the upper extremities consists of two oblong basins, of various sizes; they are placed in a hollow of the mattress near the edge of the bed, so that, as the patient lies on his back, the arm may rest comfortably in them. The reservoir for the leg is triangular; the base is directed npwards, and the apex is fixed on a board, and moves on a hinge. By means of a wooden structure, which works into the supporting board, and is tixed at the upper end, the latter can be raised on depressed at convenience. The whole apparatus forms a donble inclined plane, on which the leg, bent at an angle of about $120^{\circ}$, rests in the water. The basin has a cover, fastened down, with an opening at the upper part to admit the leg. The opening has a projecting border, on which is tixed one end of a sleeve of vulcanised caoutchouc, the other end embracing the thigh and leg; in this way, the evaporation and cooling of the water are prevented. In the interior of the reservoir, three straps are fired to hooks, so as to sustain the limb; while two other straps pass over the limb and keep it in position. At the bottom of the beth is a short tube, with a stup-cock, for remoring the water. Two openings, with moveable coverings, are made in the cover of the apparatus; one being for introdueing water, and the other for receiving the thermometer.

Injuries of the knee, and the stump after amputations of the thigh, require the horizontal position, and eonsequently another form of apparatus. This consists of a square zinc box, from halfa yard to a yard in length, fourteen iuches wide, and arranged internally in the sate manner as the apparatus already described. For stumps, the wall which looks towards the thigh bes a large 